\title{
CONSERVATION THROUGH UTILISATION: AN ANALYSIS OF INDIGENOUS ON FOREST RESOURCES FOR LIVELIHOOD SUPPORT IN THE MIDDLE HILLS OF NEPAL
}

\author{
K. P. Aryal \\ ${ }^{1}$ International Centre for Integrated Mountain Development (ICIMOD), G.P.O. Box 3226, Nepal \\ karyal@icimod.org, Tel- +977 15003222, Fax- +977 15003277
}

\begin{abstract}
The principle aim of this paper was to analyze the richness, status and contribution of uncultivated plants for the livelihoods of two indigenous ethnic groups of Nepal. The uncultivated plants are used for foods, medicines, and for cultural and economical reasons. Initially, exploratory techniques such as diversity fairs, key informant interviews and group discussions were conducted, followed by more detailed household surveys. A total of 105 households (62 in Dhading and 43 in Kaski) were included. Altogether 112 plant species were documented; including 61 species with multiple functions as food, vegetables, and medicines. The highest richness of uncultivated plants (99) was found in the forest environments. Uncultivated foods contributed significantly to food requirements and filled the gap of about 2 months per year. More than $58 \%$ of the households in Dhading use these resources at least 3.5 months a year compared to $5 \%$ in Kaski. Many species have large cultural importance and are important source of local medicines. The availability of these resources has been declining over time. However, people have started conservation and management initiatives. The uncultivated plant species are crucial to both ethnic groups, but are neglected by authorities.
\end{abstract}

Key words: Uncultivated plants, diversity fairs, richness, culture and tradition, in-situ conservation, domestication

\section{INTRODUCTION}

Uncultivated foods form an integral part of the daily diets of many rural households (Shrestha 2001) which significantly contribute in the food requirements.

ly with wild, naturalized, and non-cultivated plants. In this study uncultivated plants are wild or uncultivated plant resources, which are harvested or collected, from natural and semi-natural environments, for the purpose of human use.

Nepal is endowed with very high biodiversity due to the extreme variations in topography, climatic conditions, and presence of a great variety of ecosystems and habitats. Over $90 \%$ of the Nepalese people live in the interface between farmland and forest and depend on natural

them (Manandhar 2002). Livelihoods of the people primarily depend on an integration of forest, livestock and agricultural component and could not be sustained without them. Forest recourses are important for food, fodder and shelter as well as medicines and income. Majority of the Nepalese people are heavily dependent on uncultivated plant resources for their subsistence. Traditionally, people have considered forest resources as a source of life and a symbol of creation). Shrestha (2001) reported that uncultivated plant resources contributed about 20-30 per cent of the food needs of a household in rural communities of Nepal. A number of uncultivated plant species have been used by many rural households for their daily life; however, detailed studies regarding their availability, status, and contribution to the livelihood support are lacking. The value and potential of uncultivated foods in the food security and nutrition of rural people is also neglected in research and development programmes. Hence, an effort was necessary to document and integrate the issues regarding the uncultivated plants and their role in livelihood support as well as maintenance of these species in situ and on-farm. This study is primarily focussed to assess the richness of 
uncultivated plants, their present status and role in contribution to the livelihood support of the indigenous peoples in middle hills of Nepal.

\section{MATERIALS AND METHODS}

\subsection{STUDY SITES AND STUDY POPULATION}

The study was carried out in two indigenous ethnic groups: Chepang in Dhusa and Gurung in Hangsapur Village Development committees (VDC) of Dhading and Kaski Districts of middle hills of Nepal respectively (Fig.1).
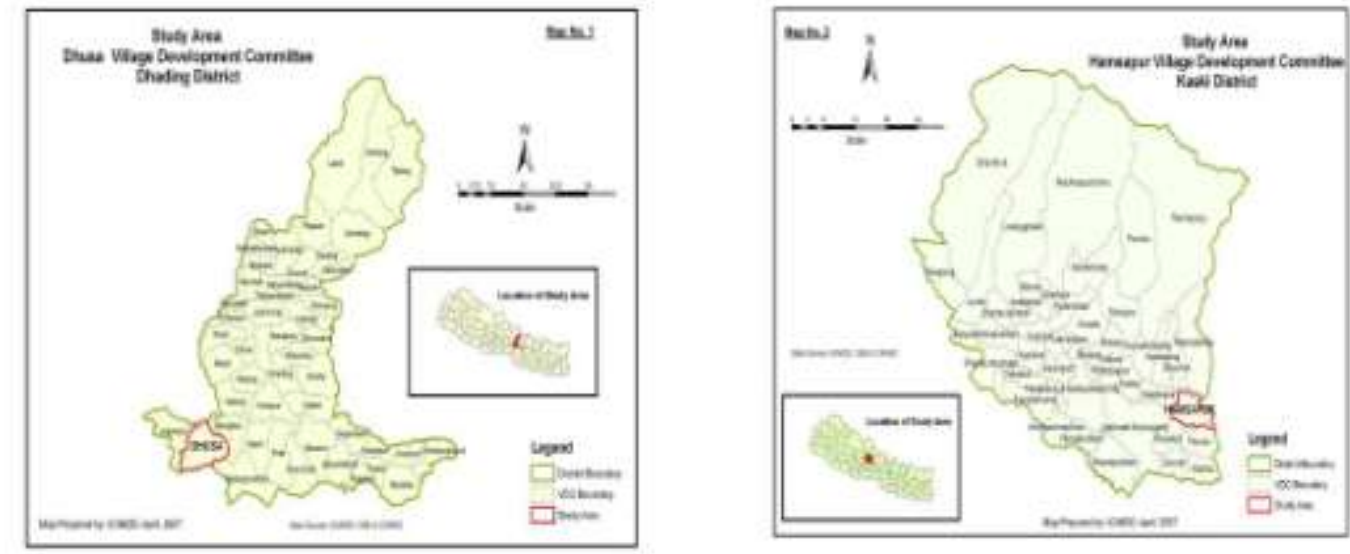

Figure 1: Study area: Dhusa VDC of Dhading district and Hangsapur VDC of Kaski

The Dhusa study area is highly fragile and difficult terrains close to the forest and the households are highly scattered. The total household number of the VDC is 1012 (CBS 2003) out of which only around 350 households are of Chepang (Chepang district profile, Dhading 2006). These households are scattered in 8 wards of the VDC. Chepangs whose population is about $52,000(0.23 \%$ of total population of the country) with only 13.9 per cent literate are the ancient settlers in the region. Chepang are traditionally hunters and lived semi-nomadic depending on shifting cultivation farming systems supplemented with hunting and gathering of wild foods (Gurung 2006).

The second site is Hangsapur VDC of Kaski district. Hangsapur Village Development Committee (VDC) is situated the north-east from the district headquarters. The total household number in the VDC is 1261 (CBS 2003). Gurung whose population is about 543 000 ( $2.4 \%$ of the national population) with 46.9 per cent literate are one of the indigenous ethnic groups of Nepal. They are the major ethnic group of the study area. They have their own language and are largely concentrated to the hill districts of Nepal. Agriculture, including animal husbandry is their main occupation.

\subsection{METHODS}

Both qualitative and quantitative data have been gathered. Individual Household surveys, key informants interview, group discussion, diversity fairs, field observation, were used. Besides, literature review was carried out extensively before the commencement for the field data collection. Household survey is basically design to know about existing farming practice, livelihood dependency, use of uncultivated plants and their management, role of gender in decision making as well as personal demographic features, was one of the major source of information. The process of household selection was completed in two stages, first, wards (9 
wards are there in one VDC) were selected VDCs and second, at least $40 \%$ of household were randomly for individual household survey. Considering the probability that some of the household representatives might not available for interview for an additional 5\% of the households were included.

A total of 105 households (62 in Dhading and 43 in Kaski) were randomly selected for the household survey. As each household represented a sampling unit, one household member who was involved in agriculture was selected as a respondent for the household survey. Besides, diversity fair were also organised in both the sites with the objective to assess the richness (no. of species), status of uncultivated plants in the study sites, and locate custodians of biological resources. Diversity Fairs provide unique opportunities to individuals and community members to display their local plant material, as well as to share and document associated knowledge (Sthapit et al.2003). Important plant specimens were collected for group discussions regarding habitat, uses of the plants, etc. Ten key informants (Seven from farmers and three from institutions working in the area) and three focussed group discussions were organised to know the general use of the uncultivated plants as well as to verify and elaborate upon the information obtained from the household survey. In addition field observation and interaction with the local people wherever possible were employed to gather additional information.

\section{RESULTS AND DISCUSSIONS}

\subsection{GENERAL CHARACTERISTICS OF RESPONDENTS}

Farmers in the study areas live under different demographic and socio-economic conditions in terms of education, income sources, food sufficiency levels, family size, age and occupation. Overall, the number of interviewed men (52.4\%) and women (47.6\%) did not differ significantly. The mean age of all respondents was 44 years, and 39 and 50 years for Dhading and Kaski, respectively. The average household size (number of people) in Kaski (6.7) and Dhading (6.5) was also similar. The household size of both districts is higher than the national average (5.4) (CBS 2003). In general, the literacy rate in the study sites was low. Slightly more than half of the total respondents were illiterate (54\%). Comparatively, illiterate respondents were more common in Dhading (72.6\%) than in Kaski (27.9\%). In total, 26.7\% of the respondents were found to be just literate which is half of the national literacy rate i.e $54.1 \%$ (CBS 2003).Agriculture is the main source of livelihood for majority of the households in the two study areas and was ranked as the most important occupation by the overwhelming majority of the respondents $(97 \%)$. However, agriculture was not sufficient to sustain their livelihoods throughout the year. About $86 \%$ of the respondents in Dhading ranked wage labour as the second most important occupation, while $51 \%$ in Kaski ranked pension/remittance as the second most important income source. The overall mean annual household income was \$593 in the study area, but the mean household income in Kaski (1147 US\$) was more than five times higher than in Dhading (209 US\$). Only $10 \%$ of households were enjoying food sufficiency from their own production. Overall, about $22 \%$ of the households produced food sufficient for more than 10 months a year, whereas majority of the households $(65 \%)$ experienced food self sufficiency between 7-10 months a year. However, the level of food self-sufficiency varied significantly between sites (Mann Whitney U-test, $\mathrm{Z}=2.9$, $\mathrm{p}<0.01$ ). During the food deficit months, this household adopts different coping strategies to meet their food demands. Share cropping (i.e. growing of crops on land owned by others), wage labour, selling of livestock, collection of wild foods, and local business were major strategies adopted by the people in order to survive food during scarcity periods.

\subsection{RICHNESS OF UNCULTIVATED PLANTS}

A total of 112 uncultivated plant species were documented during the diversity fair. Moreover, a similar number of species was used in the Kaski (99) and Dhading districts (85),

Proceedings of the 15 ${ }^{\text {th }}$ International Forestry and Environment Symposium, 26-27 November 2010. 
with a large number of species ( 73 species) used in both districts. The greatest richness of the uncultivated species was found from the forest environments (99). Uncultivated plant species contribute significantly to the livelihoods of the indigenous groups like Chepang people in Dhading and the Gurungs in Kaski (Aryal 2007). Several of the species have multiple use value. Maximum number of species (61) of uncultivated plants was found with the multiple functions (food, vegetables, medicines etc) followed by medicinal use (22) (see fig.2).

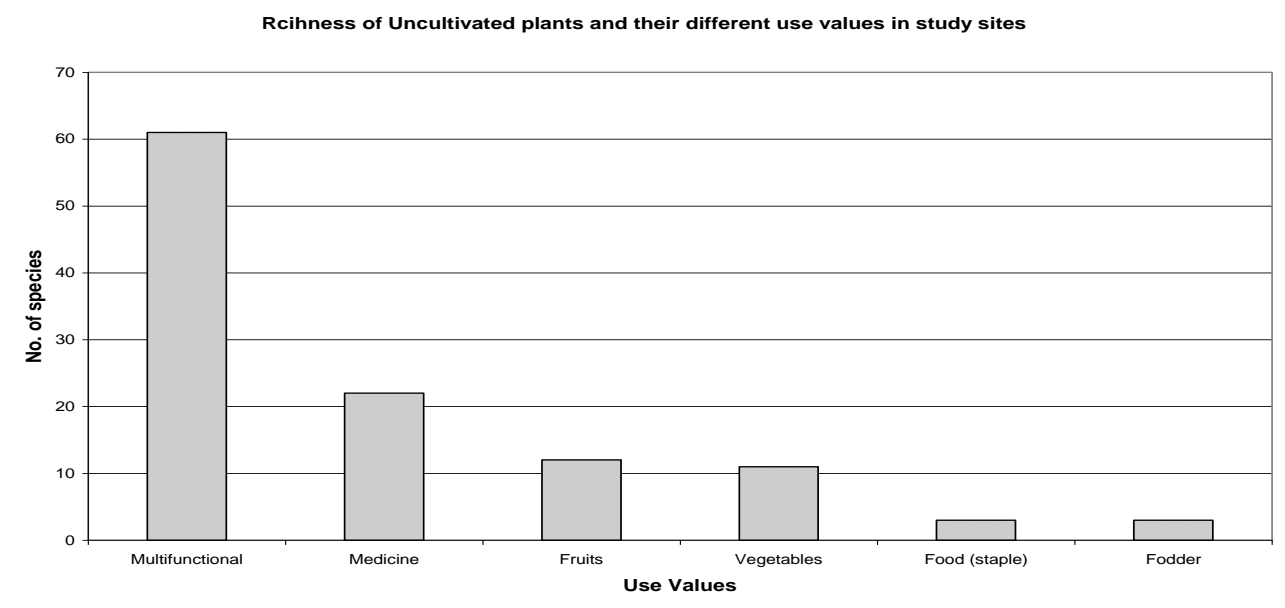

Figure 2: Richness and multiple functions of uncultivated plants

\subsection{WHAT UNCULTIVATED PLANTS CAN OFFER?}

Uncultivated plants are the source of the subsistence livelihoods to hundreds of millions of people in the form of food, materials for clothes and shelter (Cunningham 2001). These plants provide diversity in local food systems, reinforce culture and introduce diversity in farming systems, practices and traditions which are so critical for household food security, medicinal purposes, and nutrition and income generation throughout the developing countries. Some of the broad areas which uncultivated foods can offer are discussed briefly on following sections.

\section{a. FOOD AND NUTRITIONAL SECURITY}

The uncultivated foods contributed significantly to food requirement of the households in the study areas. The overall contribution was about 2 months a year, with a significant difference between Kaski (1.3 months) and Dhading (2.6 months). In Dhading, $58 \%$ of the households used food from uncultivated sources more than 3.5 months per year, while only $5 \%$ of households in Kaski used these food resources >3.5 months. A similar contribution from uncultivated foods have been found in the study carried out by Balla et al. (2002) in Tanahun and Chitwan districts of Nepal. The importance of uncultivated foods is supported by studies in other countries and regions of the world. For instance, a study carried out in India, where most of the rural people, especially the poor consume uncultivated crops at least 50-80 days in a year although these resources used to have larger importance (DDS 2002). Similarly, data from rural communities in Bangladesh illustrate that $40 \%$ of the food requirement come from uncultivated foods (Shore 2000). Thus, contributions made to the food supply of farm households by uncultivated plants are substantial but they vary from region to region. In general the dependency on uncultivated foods was significantly higher in Dhading than in Kaski (Fig.3). 


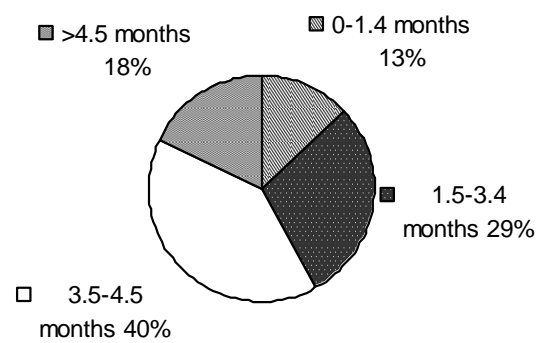

B. Kaski

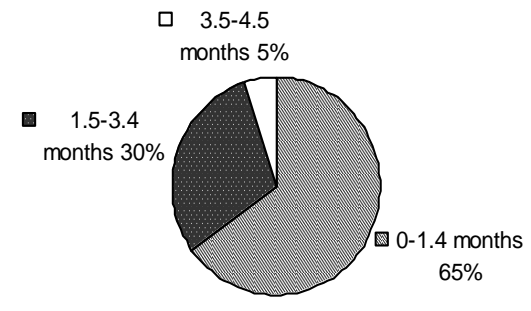

Figure 3: Contribution of uncultivated foods in daily life by districts

The local perception regarding the uncultivated and wild foods is found very nutritious and tasty. A study carried out by Hokoido University, Japan, for example, showed that the root crops Gittha and Bhyakur (Dioscorea spps.), contain five times more protein and fibre than potato and sweet potato. The study further showed that important elements like iron, calcium and phosphorus are also available in the wild foods. Many households in the study area rely heavily on wild and uncultivated plants for energy and micronutrients. However, despites its high mineral and nutrient supply, nutritional composition of most of the uncultivated foods is not known.

\section{b. OPPORTUNITIES FOR INCOME GENERATION}

Income derived from the collection and sale of uncultivated foods is particularly important for the rural poor as a source of cash income. A number of wild-food plants are of economic value and are traded on markets. However, uncultivated plants were not a major source of income in the studied regions, but people have started to market some species with potential market value. Only $11.3 \%$ of the households in Dhading have started marketing of these species, although in a low amount at present but with significant potential in the future as the demand arises in the market in certain areas. The apan, 
festival celebrated in India in December, when most of the cereals and grain crops are at maturity stage. The farming community worships mother earth by walking around a field, singing special songs while offering food specially made from more than twenty uncultivated greens. A major reason for this celebration of diversity is the fact that uncultivated foods traditionally have been the source of food for the poor (Yesudas 2004).

\subsection{COMMUNITY PERCEPTION REGARDING THE STATUS OF UNCULTIVATED PLANTS AND THEIR USE}

uggested that the availability of the uncultivated foods from the area has declined during the last 40 years. More than $70 \%$ of the informants mentioned that the major reasons for such changes were the depletion of the natural vegetation and uncontrolled harvesting as well as a heavy dependency of local people on uncultivated plants. Furthermore perception of people regarding reasons to the decreasing of uncultivated plant species was similar in both study areas. Deceasing forest cover, heavy dependency of people on forest resources, illegal harvesting and trade were suggested as the major causes of declining abundance of these species. On the other hand, a group of older people during the group discussion mentioned that changing human lifestyle and taste, negligence of traditional methods, availability of foods in the market and development of transport systems are the factors motivating people, especially the younger generation, to use more readymade fast foods. These factors have often been cited as underlying causes of a decline in use of uncultivated resources by various studies (Akhtar 2001). Thus, the use of uncultivated foods is likely to decrease in the future, and important factors contributing to livelihood, culture and tradition are vulnerable to loss

\subsection{CONSERVATION AND MANAGEMENT OF UNCULTIVATED PLANT RESOURCES}

The study shows that people in both districts have been using uncultivated resources for generations. Conservation and sustainable use of uncultivated foods have, however, received relatively little attention in research and development activities (Shrestha 2001).

Farmers are aware about management and utilizations of uncultivated plants. Ninety eight percent of the respondents in Dhading and 93\% in Kaski reported that they are involved in management of important uncultivated plant species. It was also believed that farmers will only conserve those species which they see benefit out from it. People have started in-situ conservation, domestication and/or restriction in the use of these resources. The study reported that in-situ management as a major strategy for conservation of the uncultivated species (98\% in Dhading and 90\% in Kaski). Another approach in management was domestication, which was reported to be used by $71 \%$ of the respondents in Dhading and $60 \%$ in Kaski. However, sustainable use and management is still a prime concern.

In these circumstances, maintenance and use of these uncultivated resources are therefore more important than just for botanical study. Uncultivated plants remain as important resources. Therefore, continuous study and updated inventories and information of these resources in terms of availability and use are essential. Just think what a tragedy it would be if people like Chepang, who are maintaining their livelihoods by the combination of different strategies like gathering of uncultivated foods, hunting, wage labour and subsistence agriculture (Shifting cultivation), lost one of the key components of their food i.e. uncultivated plants. 


\section{CONCLUSIONS}

This study has revealed that uncultivated plant species used for consumption at times of food shortage have the potential to become valuable staple foods and important alternatives to the usual food crops cultivated by farmers. The option to improve food production by exploiting the potential of uncultivated food plants might be a sustainable, cheap and local alternative for decreasing the food shortage problem. At the same time, promotion of use and proper management of uncultivated food plants might contribute to local biodiversity. There is a need of integrated research and development programmes where uncultivated foods are key supplements to the main diet and are of great medicinal and cultural importance. Without the understanding of the complementarities between staple food crops and uncultivated food intake, a few cultivated crops will continuously dominate the farming system and important species of uncultivated plants will remain excluded from the system.

The contribution of uncultivated plants needs to be taken into account in conservation and development planning. Since the majority of families involved in the use of such species are poor, the investment in the development of these resources will make a major contribution to the alleviation of poverty. However, additional investigations on the use and availability of uncultivated plants in different regions and countries are needed.

\section{ACKNOWLEDGEMENTS}

I would like to thank all the respondents and community members of the study sites who patiently shared their time, insights and views about uncultivated foods with the study teams. Enumerators Amber, Anil, Buddhi, Dhruba, Gyanbandhu, Madhu, Krishna, Lekhnath and Prakash are highly acknowledged for their support in data collection. I would like to thanks ICIMOD for providing facility to prepare this paper. Last but not least, Swedish Biodiversity Centre (CBM) and Swedish International Development Agency (SIDA) for financial support for this study.

\section{REFERENCES}

Akhtar, F., 2001. Uncultivated food in th Experience, in: Johnston, M.M. (Eds.), Proceedings of the regional workshop on Uncultivated Foods and Biodiversity, Kathmandu, Nepal 24-26 September 2001. 8-17

Aryal, K.P., Berg A., Ogle B.M., 2009. Uncultivated Plants and livelihood support- a case study from the Chepang people of Nepal. J. Ethnobotany Research and Application. 7, 409-422.

Aryal, K.P., Regmi, B.R., Shrestha, P.K., Tamang, B.B., 2007. How can research and development help upland farmers improve their farming systems? Experiences in participatory technology development, in: L. Gebbie, A. Glendinning, R. Lefroy-Braun \& M.Victor (Eds.), International Conference on Sustainable Sloping Lands and Watershed Management: linking research to strengthen upland policies and practices. NAFRI, Vientiane, Laos 12-15 December 2006. 287-302

Balla, M.K., Awasthi, K.D., Shrestha, P.K., Sherchan, D.P., Poudel, D., 2002. Degraded Lands in Midhills of Central Nepal: A GIS appraisal in quantifying and planning for sustainable rehabilitation. LIBIRD, Pokhara, Nepal.

CBS.,2003. Statistical Year Book of Nepal. Central Bureau of Statistics, National Planning Commission Secretariat, HMG/Nepal. Kathmandu, Nepal.

Chepang District Profile., 2006. A Socio-economic and demographic information of Chepang in Dhading districts. (Un published) 
Cunningham, A.B., 2001. Applied Ethnobotany: People, wild plant use and conservation. Earthscan Publications Ltd, London. 60-85

Deccan Development Society. 2002. Harvard System (online). Uncultivated food and poor, Published in India together. Available from: http://www.indiatogether.org/agriculture/dds/uncultivated.htm Accessed 30 September 2010

Gurung, B., 2006. Voice of Chepang, Chepang Mainstreaming Programme, a brief introductionKathmandu Nepal. 4-10

Manandhar, N.P., 2002. Plants and people of Nepal, second ed. Portland, Oregon, USA. 15-41

Pieroni, A., Nebel, S., Sanroro, R.F., Heinrich M., 2005. Food for two seasons: Culinary uses of noncultivated local vegetables and mushrooms in a south Italian village. J. of Food Sciences and Nutrition. 56(4), 245-272.

Shore, K., 2000. Harvard System (online). Protecting uncultivated food sources in south Asia. Available from: http://www.idrc.ca/en/ev-5295-201-1-DO_TOPIC.html Accessed 30 September 2010.

Shrestha, P.M., Dhillion, S.S., 2006. Diversity and traditional knowledge concerning wild food species in a locally managed forest in Nepal. J. of Agro-forestry Systems. 66, 55- 63.

Shrestha, S.R., 2001. The state of Uncultivated Foods in Nepal Biodiversity and Uncultivated food plants. in: Johnston, M.M. (Eds.), Proceedings of the regional workshop on Uncultivated Foods and Biodiversity, Kathmandu, Nepal 24-26 September 2001. 33-39

Sthapit, B., Rijal, D., Ngoc De, N., Jarvis, D., 2003. A role for diversity fairs: Experiences from Nepal and Vietnam, in: Conservation and Sustainable use of Biodiversity. A source book. Strengthening local anagement of biodiversity. Edited by International Potato Center. CIPUPWARD, Los Baños, Philippines. 271-276

Yesudas, B.S., 2004. Conservation of uncultivated foods by local communities, in: LEISA India. 6 (1), 18. 